\title{
Prospective study of fetomaternal outcome in epilepsy in pregnancy in a tertiary care hospital
}

\author{
Raji C., Sekar D.* \\ Department of Obstetrics and Gynecology, Thanjavur Medical College, Thanjavur, Tamil Nadu, India
}

Received: 31 August 2017

Accepted: 25 September 2017

\section{*Correspondence:}

Dr. Sekar D.,

E-mail: sekardeiva@yahoo.com

Copyright: $\odot$ the author(s), publisher and licensee Medip Academy. This is an open-access article distributed under the terms of the Creative Commons Attribution Non-Commercial License, which permits unrestricted non-commercial use, distribution, and reproduction in any medium, provided the original work is properly cited.

\begin{abstract}
Background: Epilepsy is the second most common neurological disorder in obstetrics after migraine. There are conflicting reports about the effect of epilepsy on pregnancy. Objective of present study was to evaluate fetomaternal outcome in patients with epilepsy.

Methods: This prospective study was conducted in Government Thanjavur medical college hospital, Tamil Nadu, India over a period of 15 months from January 2015 to March 2016 in all epilepsy cases. Total 110 epilepsy cases were admitted. In all cases maternofetal outcome were noted.

Results: This study showed that the incidence of epilepsy in pregnancy in our hospital is $0.6 \% .86 .36 \%$ of patients were treated with antiepileptic medications during their pregnancies. Pregnancy complications were anemia, gestational diabetes mellitus, gestational hypertension, intrauterine growth retardation, premature rupture of membrane, and vaginal bleeding. Live birth rate was $91.82 \%$. Low birth weight babies were recorded in 24 (21.82\%) infants. Only one baby had congenital anomaly of cleft lip and palate.

Conclusions: There was no significant increase in the risk of complications of pregnancy or delivery.Frequency of cesarean section is not increased in epileptic patients. There is no undue risk to pregnancy and childbirth in most of the cases.
\end{abstract}

Keywords: AED- antiepileptic drugs, Epilepsy, Maternal outcome, Pregnancy

\section{INTRODUCTION}

Epilepsy is the most commonly encountered neurological disorder in Obstetrics after migraine. Incidence of seizure disorder in pregnancy is estimated to be $0.3-0.5 \%$ of all births. ${ }^{1}$ Pregnancy with epilepsy is considered high risk mainly due to teratogenic potential of antiepileptic drugs and increased risk of pregnancy and neonatal complications like hypertension, preeclampsia, antepartum hemorrhage, caesarean delivery, still births, neonatal deaths, intrauterine growth restriction and preterm delivery. However, several studies have also been published that no significant increase in these complications in pregnancy with epilepsy. ${ }^{2-4} \mathrm{~A}$ few studies have focused on the effect of pregnancy on epilepsy and a possible worsening of epilepsy during pregnancy, but there are studies which do not show increase in seizure frequency during pregnancy and puerperium. ${ }^{5-7}$ About 2.5 million women in India suffer from epilepsy, with $52(25 \%)$ of them being in the reproductive age group. ${ }^{8}$ Majority of women with epilepsy will have normal, healthy infants. Effective preconceptional counseling and medical care is essential for the treatment of the pregnant women with epilepsy.., 10 Exposure to AED has been associated with two to three times increase in major malformations in infants exposed in utero as compared to the ordinary population. We report an observational prospective study of fetomaternal outcome in pregnancy with epilepsy attending a tertiary care hospital. 


\section{METHODS}

This prospective study was conducted over a period of 15 months from January 2015 to March 2016 at department of obstetrics and gynecology of Government Thanjavur medical college hospital, Tamil Nadu, India. Total 110 epilepsy cases were included in this study. These patients were managed with a team of neurologist, obstetrician, radiologist and a neonatologist.

Maternal variables analysed were age, parity, duration of epilepsy, seizure during pregnancy, antiepileptic drug usage in pregnancy, maternal complications and mode of delivery. Fetal outcome variables observed were number of live birth, still birth, birth weight, Apgar score, observation of congenital anomalies and other perinatal complications. Maternal and fetal outcome variables were presented as frequencies and percentages.

\section{RESULTS}

In this study, 110 epilepsy patients were included. The incidence of epilepsy in pregnancy in our hospital is $0.6 \%$.

Table 1: Maternal age.

\begin{tabular}{|ll|l|}
\hline Age distribution & No. & Percentage \\
\hline$<21$ years & 10 & 9.10 \\
\hline $21-25$ & 53 & 48.18 \\
\hline $26-30$ & 24 & 21.81 \\
\hline $31-35$ & 18 & 16.36 \\
\hline$>35$ & 05 & 4.55 \\
\hline Total & 110 & 100 \\
\hline
\end{tabular}

Maximum number of cases $53(48.18 \%)$ were in the age group between 21-25 years. Most 58 (52.73\%) of the cases were primigravida.

Table 2: Distribution of parity.

\begin{tabular}{|c|c|c|}
\hline Parity & No. & Percentage \\
\hline P0 & 58 & 52.73 \\
\hline $\mathrm{P} 1$ & 25 & 22.73 \\
\hline $\mathrm{P} 2$ & 16 & 14.55 \\
\hline P3 & 5 & 4.54 \\
\hline P4 and above & 6 & 5.45 \\
\hline Total & 110 & 100 \\
\hline
\end{tabular}

Table 3: Duration of epilepsy.

\begin{tabular}{|lll|}
\hline No. of years & No. & Percentage \\
\hline$<1$ year & 8 & 7.27 \\
\hline $1-5$ & 34 & 30.91 \\
\hline $6-10$ & 22 & 20 \\
\hline $11-15$ & 19 & 17.27 \\
\hline$>15$ & 27 & 24.55 \\
\hline Total & 110 & 100 \\
\hline
\end{tabular}

Most 68 (61.82\%) had epilepsy of more than 5 years. 15 patients had seizure during pregnancy. Of which 2 had new onset seizures. Among 110 patients, 15 patients were not on any anti-epileptic drugs.

Table 4: Seizure during pregnancy.

\begin{tabular}{|l|l|}
\hline Duration of epilepsy & No. of patients \\
\hline New onset & 2 \\
\hline$<5$ years & 7 \\
\hline $5-10$ years & 1 \\
\hline$>15$ & 5 \\
\hline Total & 15 \\
\hline
\end{tabular}

37 patients received more than one drug. Among the maternal complications, $38(35.43 \%)$ cases had complications. Of which Gestational hypertension was the commonest which occurred in $22(20 \%)$ patients. Premature rupture of membrane (PROM) occurred in 8 $(7.27 \%)$ cases.

Table 5: Antiepileptic drugs in pregnancy.

\begin{tabular}{|lll|}
\hline Drug & No. & Percentage \\
\hline No treatment & 15 & 13.64 \\
\hline Carbamazepine & 35 & 31.82 \\
\hline Levitriacetem & 11 & 10 \\
\hline Sodium valproate+Clobazem & 4 & 3.64 \\
\hline Sodium valproate & 8 & 7.27 \\
\hline Phenytoin+clobazem & 4 & 3.64 \\
\hline Carbamazepine+clobazem & 25 & 22.73 \\
\hline Phenytoin sodium & 3 & 2.73 \\
\hline Sodium valproate+Levodopa & 1 & 0.90 \\
\hline Lamotrigine+clobazem & 3 & 2.73 \\
\hline Topiramate & 1 & 0.90 \\
\hline Total & 110 & 100 \\
\hline
\end{tabular}

Abruptio placenta occurred in $3(2.72 \%)$ cases. 3 cases each had Gestational Diabetes and Hypothyroidsm. Other associated maternal problems like Bell's palsy, Neurofibromatosis, Systemic Lupus Erythematosis (SLE) with Ventricular septal defect (VSD), Myoclonus, Tuberous sclerosis, H/O head injury and meningitis were present in 10 cases.

Table 6: Maternal complications.

\begin{tabular}{|l|l|l|}
\hline Complications & No. & Percentage \\
\hline Gestational hypertension & 22 & 20 \\
\hline Abruption placenta & 3 & 2.72 \\
\hline PROM & 8 & 7.27 \\
\hline GDM & 3 & 2.72 \\
\hline Hypothyroid & 3 & 2.72 \\
\hline Total & 38 & 35.43 \\
\hline
\end{tabular}

1 patient died of acute Pulmonary edema due to severe pre-eclampsia 5 days after discharge from hospital. Among the mode of delivery, 5 cases had spontaneous abortion. 
Vaginal delivery was the commonest mode of delivery. $74(67.27 \%)$ cases had vaginal delivery. Caeserean delivery occurred in $31(28.18 \%)$ cases.

Table 7: Maternal mortality.

$\begin{array}{lll}\text { Mortality } & \text { No. } & \text { Percentage } \\ & 1 & 0.90\end{array}$

Acute pulmonary edema due to severe preeclampsia.

Table 8: Other maternal factors.

\begin{tabular}{|ll|}
\hline Factors & No. \\
\hline Bells palsy & 1 \\
\hline Neurofibromatosis & 2 \\
\hline $\begin{array}{l}\text { Systemic lupus erythematosis with } \\
\text { ventricular septal defect }\end{array}$ & 1 \\
\hline Myoclonus & 1 \\
\hline Tuberous sclerosis & 1 \\
\hline H/O Head injury & 3 \\
\hline H/O Meningitis & 1 \\
\hline Total & 10 \\
\hline
\end{tabular}

In fetal outcome, live birth occurred in 96 (91.43\%) cases. Intrauterine Fetal death (IUFD) occurred in 9 $(8.57 \%)$ cases. 22 babies had birth weight $<2.5 \mathrm{~kg}$. Most of the babies had birth weight $>2.5 \mathrm{~kg}$.

Table 9: Mode of delivery.

\begin{tabular}{|lll|}
\hline Mode of delivery & No. & Percentage \\
\hline Labour natural & 69 & 62.72 \\
\hline Forceps & 3 & 2.73 \\
\hline Ventouse & 2 & 1.82 \\
\hline Caesarean section & 31 & 28.18 \\
\hline Abortion & 5 & 4.55 \\
\hline Total & 110 & 100 \\
\hline
\end{tabular}

Table 10: Fetal outcome.

\begin{tabular}{|lll|}
\hline Outcome & No. & Percentage \\
\hline Live birth & 96 & 91.43 \\
\hline Still birth & 9 & 8.57 \\
\hline Total & 105 & 100 \\
\hline
\end{tabular}

Prematurity occurred in 12 (11.43) babies. IUGR in 10 babies, Birth asphyxia in 2, Neonatal death in 2.

Table 11: Birth weight and Apgar.

\begin{tabular}{|lll|}
\hline Weight in $\mathrm{Kg}$ & No. & Percentage \\
\hline$<2 \mathrm{~kg}$ & 9 & 8.57 \\
\hline $2-2.4$ & 13 & 12.38 \\
\hline $2.5-3$ & 74 & 70.48 \\
\hline$>3$ & 9 & 8.57 \\
\hline Total & 105 & 100 \\
\hline APGAR at 1 minute & $7.28 \pm 0.89$ & \\
\hline APGAR at 1 minute & $9.29 \pm 0.78$ & \\
\hline
\end{tabular}

Congenital anomaly (cleft lip/ cleft palate) occurred in one baby. All the neonates received intramuscular Vitamin K after delivery.

Table 12: Perinatal outcome.

\begin{tabular}{|lll|}
\hline Outcome & No. & Percentage \\
\hline Low birth weight & 22 & 20.95 \\
\hline Prematurity & 12 & 11.43 \\
\hline Still birth & 9 & 8.57 \\
\hline $\begin{array}{l}\text { Intra uterine growth } \\
\text { restriction (IUGR) }\end{array}$ & 10 & 9.52 \\
\hline Birth Asphyxia & 2 & 1.90 \\
\hline $\begin{array}{l}\text { Neonatal death } \\
\begin{array}{l}\text { Congenital anomaly } \\
\text { (Cleft lip and palate) }\end{array}\end{array}$ & 2 & 1.90 \\
\hline
\end{tabular}

\section{DISCUSSION}

The review of literature shows vast majority of cases are uncomplicated but there are increased obstetric risks and increased adverse neonatal outcome when compared to general population.

After the diagnosis of pregnancy, the regimen should be reassessed and monotherapy rather than polytherapy should be prescribed to minimize the risk of complications.

Pregnant women with epilepsy have a $4-8 \%$ chance of giving birth to a child with a major malformation as compared to only 2 to $4 \%$ of the general population. ${ }^{9-11}$ Frequency of seizures is increased during pregnancy in one-third of women with epilepsy. ${ }^{9,13}$

The type of anomalies occurring in infants born to pregnant women with epilepsy are orofacial clefts, cardiac diseases and neural tube defects which affects the child's life seriously. In pregnant mothers with epilepsy on one AED this occurs in 4 to $8 \%$ and is probably greater in those receiving more than one AED. ${ }^{11,12}$ The most common anticonvulsant used in our study was carbamazepine in $35(31.82 \%)$ patients. Studies with newer drugs show that the incidence of major malformations are not higher than with the older AEDs. ${ }^{14}$

In this study $52.73 \%$ of cases were primigravida and $47.27 \%$ of cases were multigravida as compared to study by Jeyarani et al. ${ }^{15}$ In this study, 59 cases had monotherapy. 15 cases were not on any treatment. Remaining 36 cases had combined AEDs. In this study, $95(86.36 \%)$ patients were seizure free during pregnancy as compared to other study by Malik $\mathrm{R}$ et al. ${ }^{16} 38$ cases had pregnancy related complications of which the most commonest was gestational hypertension in 22 (20\%) cases which is comparable to Goel et al study has reported PIH (24.3\%), abruption (5.4\%), GDM (2.7\%) of cases in his study. ${ }^{17}$ 
Mode of delivery in epileptic women is nearly comparable to study of Goel et al who observed normal vaginal delivery in $62 \%$ of cases and LSCS in $27 \%$ and instrumental delivery of $10.8 \% .^{17}$

In present study, the rate of cesarean section was $28.18 \%$, Labour natural in $62.72 \%$. In present study, IUGR observed in $9.52 \%$ and preterm labour in $11.43 \%$ which is comparable to Chattopadhyay et al observed IUGR $(9.3 \%)$ and preterm labour in $(9.3 \%)$ of cases. ${ }^{18}$ Neonatal bleeding can occur in mothers taking AEDs because of diminished amount of Vitamin $\mathrm{K}$ dependent clotting factors. ${ }^{19,20}$

No case of neonatal bleeding was observed in this study. In a study by Saleh AM et al in Saudi Arabia in 2008 no significant difference was confirmed for fetal complications between epileptic and non-epileptic women. $^{21}$ Preferably, WWE should be on the least possible dosage and monotherapy of AEDs at the time of conception. ${ }^{22}$ In this study, only one baby had cleft palate and cleft lip.

\section{CONCLUSION}

Pregnancy with epilepsy presents a unique challenge both for the mother and her baby. In this study we observed that though pregnancy with epilepsy needs comprehensive antenatal care and this results in uneventful pregnancies with good feto-maternal outcome.

These women should be managed with monotherapy at the lowest possible dosage to diminish the risk of complications and also maintain good seizure control. They must be subjected to high-definition anomaly ultrasound scan at 18-20 weeks. These women should be managed with mandatory folate supplementation and the neonates must be given Vitamin $\mathrm{K}$. These high risk pregnancies need spontaneous referral to tertiary care centers for better maternal and neonatal outcome. The perinatal complications can be diminished by the close coordination between the neurologist, obstetrician and the pediatrician.

\section{ACKNOWLEDGMENTS}

Authors would like to acknowledge and express my sincere thanks to our Dean, Thanjavur Medical College and hospital, Thanjavur, India for allowing to do this study and utilizing the Institutional facilities. Authors would like to all the medical and para-medical staffs who have helped to complete this study. A special thanks to all the patients who willingly co-operated and participated in this study.

\section{Funding: No funding sources} Conflict of interest: None declared

Ethical approval: The study was approved by the Institutional Ethics Committee

\section{REFERENCES}

1. Practice parameter; management issue for women with epilepsy (Summary statement) - Report of the quality standards subcommittee of American Academy of Neurology. Neurology. 1998;51:944-8.

2. Yerby M, Kogpsell T, Daling J. Pregnancy complications and outcomes in a cohort of women with epilepsy. Epilepsia. 1985;26:631-5.

3. Richmond JR, Krishnamoorthy P, Andermann E, Benjamin A. Epilepsy and pregnancy. An Obstetric perspective. Am J Obstet Gynecol. 2004;190:371-9.

4. Sawhney H, Vashishta K, Suri V, Khunnu B, Goel P, Sawhney IM. Pregnancy with epilepsy - a retrospective analysis. Int $\mathrm{J}$ Gynecol Obstet. 1996;54:17-22.

5. Knight AH, Rhind EG. Epilepsy and pregnancy: a study of 153 pregnancies in 59 patients. Epilepsia. 1975;16:99-110.

6. Tanganelli P, Regesta G. Epilepsy, pregnancy and major birth anomalies; an Italian prospective, controlled study. Neurology. 1992;42 (4 suppl 5):8993.

7. Costa AL, Lopes-Cendes I, Guerreiro CA. Seizure frequency during pregnancy and the puerperium. Inter J Gynaecol Obstet. 2005 Feb;88:148-9.

8. Thomas SV. Management of epilepsy and pregnancy. J Postgrad Med. 2006;52:57-64.

9. Nathan J. Women with epilepsy. J Obstet Gynecol India. 2004;54:543-53.

10. Jeha LE, Morris HH. Optimizing outcomes in pregnant women with epilepsy. Cleve Clin J Med. 2005;72:938-45.

11. More MJ. Epilepsy and pregnancy: minimizing the risks. Contemp Obstet Gynecol. 2004;49:51-70.

12. Meador KJ, Baker GA, Finnell RH et al. In utero antiepileptic drug exposure: fetal death and malformations. Neurology 2006;67:407-12.

13. Morrel MJ. Epilepsy in women. Am Fam Physician 2002;66:1489-94.

14. Holmes LB, Harvey EA, Coull BA, Huntington KB, Khoshbin S, Hayes AM et al. The teratogenicity of anticonvulsant drugs. New Engl J Med. 2001;344:1132-8

15. Jeyrani $P$, Indumathi $S$. Maternal outcome in epilepsy complicating pregnancy. Int J Res Health Sci [Internet]. 2014 Apr 30;2(2):488-93.

16. Malik R, Kumar V, Chaudhary S, Duhan N. Obstetric and neonatal outcome in women with epilepsy. Int J Reprod Contracept Obstet Gynecol. 2017 Jun;6(6):2593-6.

17. Goel P, Devi L, Saha PK, Takkar N, Huria A, Dua D. Maternal and perinatal outcome in pregnancy with epilepsy. Internet J Gynecol Obstet. 2006;5.

18. Nibedita C, Amitava M, Shyamapada P, Partha M, Dipankar G, Gautam G. Feto-maternal outcome in pregnancy with epilepsy in a tertiary care hospital. J Obstet Gynecol India. 2008;58(5):406-9. 
19. Meador KJ, Zupanc ML. Neurodevelopmental outcomes of children born to mothers with epilepsy. Cleve Clin J Med. 2004;71:38-41.

20. Yerby MS, Kaplan P, Tran T. Risks and management of pregnancy in women with epilepsy. Cleve Clin J Med. 2004;71:25-37.

21. Saleh AM, Abotalib ZM, Al-Ibrahim AA, Al-Sultan SM. Comparison of maternal and fetal outcomes in epileptic and non-epileptic women. Saudi Med J. 2008;29:261-6.
22. Royal College of Obstetricians and Gynaecologists. Epilepsy in pregnancy. Green- top guideline No.68. June 2016.

Cite this article as: Raji C, Sekar D. Prospective study of fetomaternal outcome in epilepsy in pregnancy in a tertiary care hospital. Int J Reprod Contracept Obstet Gynecol 2017;6:5055-9. 